\title{
EL TURISMO RESIDENCIAL NO EXISTE. REVISIÓN DE UN CONCEPTO Y CRÍTICA DE SU FUNCIÓN IDEOLÓGICA
}

\author{
Alejandro Mantecón \\ Universidad de Alicante
}

\section{RESUMEN}

Este trabajo presenta una contribución a la discusión sobre la instrumentalización ideológica que se ha hecho del turismo con el fin de promover intereses ligados al negocio inmobiliario. Con este propósito, se revisan los orígenes y evolución de la expresión «turismo residencial» en el debate académico para, después, plantear una reflexión sobre la apropiación y redefinición del concepto por parte de la llamada «burguesía cementera». Las conclusiones cuestionan los límites y la vigencia de la expresión como herramienta útil para la investigación en turismo, sobre todo si se considera la politización a la que este término ha sido expuesto.

Palabras clave: migración residencial; negocio inmobiliario; ideología; análisis del discurso.

The residential tourism does not exist. A concept review and critique of its ideological function

\section{ABSTRACT}

This paper presents a contribution to the discussion about the ideological exploitation of tourism which has been made to promote the real estate business interests. For this purpose, the origins and evolution of the expression «residential tourism» in the academic debate are reviewed. Then a reflection on the appropriation and redefinition of the concept by

Recibido: 16 de mayo de 2016

Devuelto para su revisión: 12 de diciembre de 2016

Aceptado: 28 de febrero de 2017

Departamento de Sociología I. Universidad de Alicante. 03080 San Vicente del Raspeig. ALICANTE (España). E-mail: alejandro.mantecon@ua.es 
the so-called «cement bourgeoisie» is offered. The findings challenge the limits and the validity of the expression as a useful tool for research in tourism, especially considering the politicisation to which this term has been exposed.

Keywords: residential migration; real estate business; ideology; discourse analysis.

\section{INTRODUCCIÓN}

La confluencia del turismo que se aloja en viviendas privadas con las migraciones orientadas por motivaciones más próximas a la esfera del ocio que a la del trabajo ha generado formas de movilidad y estrategias residenciales en las que se ven involucrados ciudadanos de cada vez más regiones. Así lo prueban los estudios realizados en lugares tan dispares como Panamá (Jackiewicz y Craine, 2010), Brasil (Assis, 2009), Australia (Sato, 2001), Malasia (Ono, 2008), Tailandia (Howard, 2009), India (Nigam y Narula, 2009), Turquía (Nudrali y O’Reilly, 2009), Suecia (Müller, 2002), Marruecos (Gil de Arriba, 2011) o Sudáfrica (Visser, 2004). Para referirse a esta variedad de desplazamientos la literatura científica, sobre todo la producida en inglés, ha empleado multitud de términos, dependiendo de los grupos y los comportamientos concretos estudiados o de las características que se han considerado esenciales. A continuación, y sin pretensión de exhaustividad, se enumeran algunas de las expresiones frecuentes y algunos de los autores que las han utilizado, aunque ello no implique que sean quienes las han acuñado: «second-home tourism» (Breuer, 2005; Jaakson, 1986), «long-stay tourism» (Ono, 2008), «residential tourism» (O'Reilly, 2007; McWatters, 2008), «real estate tourism» (Barrantes, 2011; Hof y Blázquez, 2013) «tourism-led migration» (Williams y Hall, 2002), «amenity migration» (Haas y Serow, 1993; Moss, 2006), «cyclical migration» (McHugh et al., 1995), «elderly migration» (Biggar, 1980; Huber y O’Reilly, 2004), «later-life migration» (Silverstein y Zablotsky, 1996; Walters, 2002), «leisure migration» (Böröcz, 1996), «lifestyle migration» (Benson y O'Reilly, 2009; Sato, 2001), «retirement migration» (King et al., 2000; Rodríguez, 2001), «residential migration» (Salvà, 2002a), «seasonal migration» (Gustafson, 2002; Hogan, 1987), «temporary migration» (Smith y House, 2007), «snowbird migration» (Longino et al., 1991), «elderly residential mobility» (Speare y Meyer, 1988), «leisure-oriented mobility» (Hall et al., 2004), «lifestyle mobilities» (Janoschka, 2009), «privileged mobility» (Croucher, 2012) o «tourism-related mobilities» (Janoschka, 2011).

La cantidad de publicaciones que han visto la luz en los últimos años dificulta reconocer hilos argumentales. No obstante, bajo esta profusión terminológica se advierte una cierta polarización en la actual aproximación epistemológica al objeto de estudio que, si bien dista mucho de agrupar a toda la literatura, sí que permite reconocer algunos rasgos sintomáticos:

Por una parte, se observa una senda, transitada principalmente por académicos anglosajones, que, sobre todo desde aproximaciones cualitativas, ha analizado los discursos elaborados por sus connacionales en relación a sus vivencias en el nuevo emplazamiento. Para estos investigadores la comprensión y definición de la realidad social ha tendido a construirse en coherencia con las interpretaciones que los nuevos residentes (es decir, sus 
entrevistados) producen a partir de su particular percepción del mundo en el que se hallan envueltos, confundiéndo a menudo el análisis de la realidad con la ilustración de un discurso subjetivo sobre la misma. Un ejemplo recurrente de esta forma de proceder lo constituyen los trabajos publicados por Karen O'Reilly tras la aparición de su libro The British on the Costa del Sol (2000). De hecho, los desarrollos teóricos en los que culminaron las investigaciones basadas en este enfoque solipsista han derivado en modelos explicativos imprecisos (ver, por ejemplo, Benson y O'Reilly, 2009), tal y como pusieron en evidencia Huete et al. (2013) a propósito del marco teórico-analítico de la «Lifestyle Migration».

Por otro lado, se distingue un camino seguido por muchos expertos que comparten como característica distintiva la formulación de análisis críticos acerca de los efectos generados en las sociedades receptoras como consecuencia de los procesos de cambio ocasionados. En el siguiente apartado se profundiza en el desarrollo de esta línea fijando la atención en el uso que se ha dado del término «turismo residencial». Así, las próximas páginas contienen una discusión en torno a dicha expresión pues, de las citadas, no solo es una de las más recurrentes en las publicaciones firmadas por hispanohablantes, también es, como se tratará de aclarar en la segunda parte del trabajo, la que ha experimentado una proyección ideológica más intensa. Es decir, representa, de los mencionados, el concepto que de modo más evidente se ha utilizado como herramienta al servicio de intereses que trascienden el análisis de la realidad social.

\section{REVISIÓN}

La investigación del llamado turismo residencial hunde sus raíces en la década de 1970. Los primeros trabajos publicados fijan su atención en las transformaciones que se producen en las regiones mediterráneas españolas como resultado de la progresiva imbricación del negocio inmobiliario con la promoción turística durante los últimos años de la dictadura franquista. Mario Gaviria es probablemente quien llevó a cabo los primeros estudios rigurosos de este proceso (Gaviria, 1974a, 1974b, 1976). Su perspectiva se sostenía sobre un análisis crítico vinculado a la sociología urbana de inspiración marxista, inspirada en su maestro Henri Lefebvre. En este sentido, el turismo basado en la construcción de viviendas privadas se presentaba como un producto destinado al consumo masivo en el marco de un sistema de relaciones asentado sobre los juegos de poder inherentes a la expansión de los mercados inmobiliarios locales e internacionales. Gaviria no empleaba la expresión «turismo residencial», pero no cabe duda de que sea ese proceso de cambio social el que examina en sus publicaciones. En esos años, el geógrafo Manuel Valenzuela (1974) publicaba un revelador artículo donde planteaba explícitamente la exploración de un proceso turístico-residencial. Otro trabajo pionero es el de José Ortega Valcárcel (1975) sobre las residencias secundarias en España. En ese estudio el autor diferenciaba tres tipos de localizaciones: el espacio residencial mediterráneo, las periferias urbanas de residencias secundarias en las grandes ciudades y los espacios residenciales de ocio no periféricos. El primero de estos tipos se correspondería con el naciente fenómeno del turismo residencial, que transformaba las regiones costeras mediterráneas mediante la construcción a gran escala de urbanizaciones de viviendas destinadas originalmente al consumo turístico. 
No obstante, se suele reconocer a Francisco Jurdao como el investigador que incorpora definitivamente este concepto al debate académico. Lo hace en su libro de 1979 España en venta: compra de suelo por extranjeros y colonización de campesinos en la Costa del Sol. Una obra que era el resultado de la elaboración de su tesis, defendida un año antes en la Universidad del País Vasco con el título Turismo residencial y colonización. Jurdao se servía del término para explicar y criticar los cambios que tenían lugar en el malagueño municipio de Mijas durante los años setenta a causa de la venta de suelo agrícola, propiedad de campesinos, a empresarios urbanizadores. Tras el cambio de propiedad, el suelo se destinaba a la construcción de urbanizaciones turísticas de chalets que, posteriormente, eran en su mayoría adquiridos por jubilados noreuropeos. También en 1978, Pere Salvà defiende en la Universidad de Barcelona su monumental tesis doctoral: Aproximación al conocimiento de la transformación del espacio rural en la Serra de Tramuntana de la isla de Mallorca. A partir de los enfoques desarrollados por Gaviria en sus libros tempranos (Gaviria, 1971, 1974b), Salvà ilustra y documenta la transformación de un espacio agrario tradicional orientado hacia las funciones productivas en un nuevo espacio residencial orientado hacia las funciones del ocio, aunque íntimamente ligadas con el negocio inmobiliario. De especial interés resulta el capítulo: «Hipertrofia del sector terciario y cambio de utilización del espacio rural como consecuencia del turismo». Con los años, este autor acabaría convirtiéndose en una figura central en la discusión sobre las dinámicas turísticoresidenciales planteando líneas de trabajo que se mostrarían muy fructíferas. La literatura anglosajona del momento ofrece como obra clave el libro de John T. Coppock Second Homes: Curse or Blessing, publicado en 1977. De hecho, los académicos de habla inglesa a menudo citan su trabajo como punto de partida de esta línea de investigación, la mayoría de las veces debido a su escaso interés por la literatura escrita en otros idiomas. Sin embargo, como indica Julio del Pino (2015: 75), el trabajo de Coppock apenas abordaba las claves explicativas fundamentales del proceso turístico-residencial, particularmente si se compara ese libro con las aportaciones anteriormente indicadas.

A principios de la década de 1980 se publica en México una monografía de investigación sobresaliente. Se trata del libro de Francisco Talavera Lago de Chapala. Turismo residencial y campesinado (1982), en el que se desgrana el proceso de acumulación de riqueza que emprenden las élites directoras del negocio turístico-inmobiliario a partir del despojo ecológico (o descapitalización) de los recursos y derechos que poseían las comunidades campesinas. Por su parte, Pere Salvà (1980, 1984, 1985a, 1985b) comienza a publicar una serie de artículos en los que da a conocer los hallazgos obtenidos en su minucioso estudio sobre las Baleares. En Norteamérica, es muy destacable la contribución realizada por Reiner Jaakson con la publicación en 1986 del artículo «Second-home domestic tourism», donde realiza una novedosa aproximación a la comprensión del fenómeno de las segundas residencias en entornos turísticos introduciendo un punto de vista fenomenológico, a medio camino entre la sociología y la psicología social, en virtud del cual intenta comprender los significados que los consumidores de este tipo de establecimientos atribuyen a la segunda residencia en contraposición con la vivienda principal. Para la producción científica en castellano resulta significativo el año 1987, momento en el que, desde la Universidad de Alicante, los geógrafos Tomás Mazón y Fernando Vera publican su tesina de licenciatura y su tesis doctoral respectivamente. El trabajo de 
Mazón se titula La Playa de San Juan: un espacio turístico-residencial, el libro de Vera es Turismo y urbanización en el litoral alicantino y sigue apreciándose como un hito en el estudio sobre las repercusiones territoriales de la expansión turístico-inmobiliaria en la provincia de Alicante.

Entre finales de la década de 1990 y los primeros años del siglo XXI tiene lugar la auténtica eclosión de la investigación académica y multidisciplinar de estos procesos, tanto en la producción científica de habla inglesa como en la de habla hispana. Lógicamente, son diversos los debates que se han provocado. Uno que resulta particularmente relevante, debido a sus implicaciones prácticas, es el que tiene que ver con la dificultad que supone precisar dónde termina el comportamiento turístico y dónde empieza el migratorio (puede rastrearse esta discusión a través de los trabajos de Aronsson, 2004; Bell y Ward, 2000; Huete y Mantecón, 2010, 2012; Casado, 2001; Leontidou y Marmaras, 2001; Monreal, 2001; Müller, 2002; O’Reilly, 2003; Rodríguez, 2001, 2004; Salvà, 2002a, 2002b, 2005; Williams y Hall, 2000, 2002; o Williams et al., 2000). Es esta una discusión todavía abierta, como lo prueba la reciente publicación de Domínguez et al. (2016) en la que, precisamente, se subrayan las dificultades existentes para solventar los desafíos metodológicos derivados de las ambigüedades teóricas.

De la lectura de las aportaciones más significativas sobre el tema se sugiere una posible diferenciación entre:

a) Aquellos estudios que han explicado el turismo residencial a partir de su concepción como una tipología o modelo turístico más o menos preciso, cuyo rasgo definitorio más evidente sea probablemente el hecho de estar necesariamente asociado a una oferta de alojamiento en viviendas privadas. Algunas publicaciones ilustrativas de esta perspectiva son las de Hiernaux (2009), Perles et al. (2016) o Raya (2003).

b) Las investigaciones que, en lugar de hablar de una modalidad o un tipo de turismo específico, abordan la cuestión conviniendo que la expresión alude a un entramado de procesos en los que múltiples formas de movilidad residencial y estrategias de transformación del espacio se integran en una lógica político-económica consistente en la edificación de viviendas en entornos de interés turístico (o publicitados como tales) y en la expansión del sector inmobiliario. En esta posición se distinguen publicaciones asentadas sobre supuestos epistemológicos muy dispares que comprenden desde aquellas que desarrollan elaboradas reflexiones teóricas a otras en las que la problematización conceptual se deja en un segundo plano, o se evita, como si, a falta de algo mejor, la expresión simplemente resultase una herramienta aceptable para nombrar y condensar el conjunto de relaciones y procesos que constituyen el objeto de los análisis. Al respecto, pueden consultarse, por ejemplo, los estudios de Aledo et al. (2013); Janoschka (2013) o Morote et al. (2016).

c) Los trabajos que, al analizar las realidades ante las que se enfrentan la mayoría de las investigaciones que estudian el turismo residencial, normalmente eluden el empleo de la expresión turismo residencial. Quizá el caso más ilustrativo de esta actitud se corresponda con la forma de abordar el asunto del más solvente de los investigadores en activo. Un dato que, en este caso, resulta relevante resaltar pues, no parece una casualidad que quien ha demostrado una trayectoria más contrastada 
en el análisis del nexo entre la urbanización y el turismo en España prefiera referirse a estas realidades empleando expresiones como «función residencial» (Vera, 2005a) o «vertiente residencial» del turismo (Vera, 2005b y 2006).

La pequeña muestra de trabajos citados únicamente pretende ilustrar los tres enfoques señalados. Estas publicaciones tienen en común el hecho de representar esfuerzos investigadores ejemplares, caracterizados por la rigurosidad y originalidad de los argumentos que contienen. Nótese que en este esbozo de categorización se alude en primer lugar a los estudios sobre el tema y, solo después, a los estudiosos del tema, pues, en realidad, no es infrecuente toparse con autores que en distintas etapas de su trayectoria investigadora, o incluso en publicaciones fraguadas en momentos muy próximos -y debido a su interés por enfatizar unos u otros aspectos-, han abordado sus trabajos desde más de una de estas posiciones, por no decir que desde las tres, como, sin ir más lejos, le ha sucedido al firmante de este texto. En todo caso, el denominador común de las tres opciones es el desarrollo de análisis desde enfoques críticos pues, en realidad, todas son herederas de una misma línea de investigación que desde sus orígenes ha orientado sus estudios aplicados con el propósito de poner de manifiesto las contradicciones inherentes al llamado turismo residencial. Desde luego, los argumentos críticos han cristalizado en actitudes más o menos asociadas a compromisos éticos, los cuales han oscilado desde el esclarecimiento del carácter poliédrico de un fenómeno que genera efectos valorados de manera ambivalente, hasta los análisis que se han vinculado a la denuncia y transformación de situaciones diagnosticadas como injustas (ilustrativos de estos últimos son, entre otros, los trabajos de Blázquez et al., 2011; Janoschka, 2011; Murray, 2015 o los ensayos compilados por Gascón y Cañada, 2016).

Pero conviene apuntar que la asociación del turismo residencial con un proceso migratorio o turístico no genera un debate restringido al ámbito académico. Especialmente, cuando esa discusión se entremezcla con otra en la que desempeñan un papel clave los discursos que emanan de las élites políticas y empresariales. Esos discursos se han puesto al servicio de estrategias político-económicas interesadas en presentar como desarrollo turístico ante la opinión pública lo que, habitualmente, ha sido estrictamente crecimiento de la edificación (tal y como han puesto de manifiesto Aledo, 2008; Díaz y Lourés, 2008; Gaviria, 1974a, 1974b; González y Mantecón, 2014; Huete y Tros-de-Ilarduya, 2011; Jurdao, 1979; Mantecón, 2011a, 2012; Mazón, 2006; Membrado, 2015; Talavera, 1982; o Vera, 2005a). En el siguiente apartado se propone una reflexión acerca del modo en el que la expresión «turismo residencial» ha sido instrumentalizada por parte de los actores sociales más interesados en la promoción del negocio inmobiliario.

\section{CRÍTICA}

\subsection{El intento de apropiación}

A finales de la década de 1990, y muy especialmente en los primeros años del presente siglo, el uso de la expresión «turismo residencial» comenzó a constituirse en un motivo de disputa que trascendía los límites de las discusiones académicas, pues la identificación con 
una herramienta analítica quedó enturbiada al ser el término reclamado y utilizado como herramienta publicitaria por parte del marketing inmobiliario. Publicaciones como las de Mantecón $(2008,2011 b)$ explican la naturaleza de las luchas discursivas conformadas entonces con el fin de establecer una interpretación hegemónica sobre el significado de la expresión. La instrumentalización publicitaria del concepto por parte de la «burguesía cementera» se comprende en el marco de las nuevas estrategias empresariales que adoptaban tanto las corporaciones del sector inmobiliario como las del turístico. Se aclara aquí que «burguesía cementera» es un término popularizado por el urbanista Jordi Borja (2003, 2012) para hacer referencia a las élites políticas y empresariales españolas que actuaban de forma integrada en las operaciones de acumulación y promoción de suelo destinado a ser urbanizado en el contexto de los años de formación de la burbuja inmobiliaria.

El proceso de descentralización político-administrativo que se inició en España en la década de 1980 conllevó, entre otros efectos, el reconocimiento de las competencias fundamentales en materia urbanística para los ayuntamientos. De tal manera, el futuro urbanístico de los territorios debía dirimirse entre los poderes locales. En los años noventa, y en un marco de expansión de la economía inmobiliaria alentada por cambios legislativos que promovían la liberalización de los usos del suelo (ver Ley del Suelo de 1998 o la ley autonómica valenciana LRAU de 1994), los empresarios constructores y las élites políticas locales no tardaron en promover todo tipo de estrategias de colaboración con el fin de facilitar la expansión de la industria de la construcción. Especial énfasis se puso en los municipios de las regiones mediterráneas, inicialmente los más atractivos para albergar productos susceptibles de ser comercializados en el mercado español y en las ferias inmobiliarias europeas. Las burguesías cementeras locales presentaban esta lógica de actuación como desarrollo del «turismo residencial», conocedoras de que es más fácil obtener el respaldo ciudadano necesario para reorientar las actividades económicas municipales hacia la especialización en actividades intensivas del sector inmobiliario si previamente se las hace pasar ante la opinión pública como de naturaleza predominantemente turística (Huete, 2004). Los procesos especulativos, desmanes y comportamientos corruptos generados por la amplificación de estas dinámicas son hoy sobradamente conocidos, como igualmente es conocida la reducción de las alternativas para el desarrollo local que han experimentado tantas localidades a causa de la degradación de su entorno ambiental y socioeconómico.

El incuestionable éxito que tuvo la instrumentalización publicitaria del uso del término «turismo residencial», particularmente durante los diez años anteriores al estallido de la burbuja, también captó la atención de los propios empresarios hoteleros que, después de comprobar la escasa efectividad de las campañas que habían impulsado en contra de la competencia desleal ejercida por la oferta de alojamiento residencial, decidieron «unirse al enemigo». Sol Meliá, uno de los buques insignia de la armada hotelera mallorquina, fue en 2004 de las primeras empresas españolas en adentrarse a gran escala en el mundo de los condohoteles a través del proyecto «Sol Meliá Vacation Club» (después «Club Meliá»). Los empresarios hoteleros también querían su pedazo del pastel inmobiliario, si bien, integrándolo en una lógica más parecida a la que cabría entender como propia de una oferta de alojamiento turístico convencional (un análisis detallado puede encontrarse en Fuster et al., 2010; Murray, 2015 y Ramón, 2002, 2010). 
La instrumentalización del concepto por parte de las élites político-empresariales ha dado lugar a una situación de aparente confusión en cuanto al significado de una expresión que, verdaderamente, refleja el intento por constituir un discurso hegemónico que definitivamente presente al turismo residencial como una actividad empresarial de naturaleza inequívocamente turística asociada en primer lugar a la producción de beneficios sociales y prosperidad económica. Si se revisa la evolución del tratamiento del concepto en Hosteltur, la revista española más influyente en el ámbito del sector turístico (se trata de una revista profesional, no académica), se aprecian cambios muy sintomáticos. No cabe duda de que el contexto socioeconómico ha cambiado desde que en abril de 2006 la revista publicara un número especial sobre el turismo residencial titulado: «Turismo residencial, la punta del iceberg», plagado de evaluaciones críticas de diversa intensidad que subrayaban el carácter alegal e informal de la economía turístico-residencial, hasta las noticias editadas en tiempos más recientes, en donde se entremezclan valoraciones críticas con otras que promueven la expansión de las actividades turístico-residenciales. Sobre las últimas puede consultarse: «Living Costa del Sol, nueva marca para promover el turismo residencial entre los británicos», editada en noviembre de 2011; «Reactivar el turismo residencial, objetivo de la Región de Murcia», editada en junio de 2012; «El turismo residencial podría absorber un tercio del stock de vivienda nueva», editada en octubre de 2012; o «Ranking de destinos más deseados de turismo residencial», editada en abril de 2014. Un denominador común de estas noticias es el hecho de hacer alusión a declaraciones emitidas no tanto desde el empresariado turístico como desde asociaciones de empresarios promotores inmobiliarios, en ocasiones apadrinadas por autoridades del ámbito político, en las que el turismo residencial se presenta como una vía de desarrollo turístico legítima para contribuir a la salida de la crisis económica. Básicamente, la idea subyacente es la que sigue: si la burguesía cementera ha visto reducida su autoridad como prescriptora a causa de los desmanes que la economía inmobiliaria intensificó hasta colapsar el sistema, el mismo entramado político-inmobiliario, aunque ahora reforzando su presentación pública como promotor del desarrollo turístico, podría igualmente ayudar a reactivarlo.

Si se introduce la expresión «turismo residencial» (en castellano o en inglés) en Google, la variedad de noticias, opiniones y artículos que aparecen hablando de multitud de realidades, valoradas de muy distintas maneras, da la impresión al lector de hallarse ante un cajón de sastre virtual. En realidad, lo que tiene ante sí es el estado en el que se encuentra un «campo» (champ, en el sentido en el que este concepto sociológico era utilizado por Pierre Bourdieu) en el que colisionan fuerzas e intereses de distintos actores sociales (empresariales, políticos y, también, académicos). Un caso ilustrativo se encuentra en la prensa del 27 de mayo de 2016, cuando el periódico alicantino Información publica la siguiente noticia: «Provia advierte de que la política contra el alquiler amenaza el turismo residencial», mientras que la edición para la Comunidad Valenciana de El Mundo también se hace eco del mismo asunto: «Los promotores piden al Consell que no endurezca las leyes sobre alquiler». Noticias en las que, esencialmente, se reconoce cómo el entramado empresarial de los medios de comunicación presta altavoces a un sector de la actividad económica inmobiliaria para que, enarbolando la bandera del interés turístico, muestre su indignación ante la pretensión de las autoridades políticas de hacer que se cumpla la ley. Lo que esas noticias no explican es que las asociaciones de empresarios turísticos 
que, desde la legalidad, se dedican a comercializar el alquiler de apartamentos para su uso turístico sí que defienden los intentos de las administraciones públicas por regular un sector en el que quienes optan por desarrollar su negocio de acuerdo a la legislación vigente se ven sistemáticamente expuestos a sufrir una competencia desleal por parte de una oferta de alojamiento ilegal que, según los cálculos estimados, multiplica por entre 4 y 7 a la oferta de alojamiento reglado (Requejo, 2007).

\subsection{El carácter hipnótico}

La expresión «turismo residencial» es un oxímoron, esto es, un concepto integrado por dos términos que aluden a realidades contradictorias: el sustantivo «turismo» implica movilidad y provisionalidad, mientras que el adjetivo «residencial» sugiere asentamiento y permanencia en un lugar. Si bien es cierto que el empleo de esta expresión en la tradición académica nunca ha dejado de provocar controversias, el hecho precisamente de que contenga y exprese un carácter contradictorio encaja con la pretensión de hacer referencia a un conjunto de actividades que generan repercusiones complejas y ambivalentes. Sin embargo, al presentarse como una etiqueta perfectamente coherente que apunta a una tipología turística generadora de riqueza y empleo se diluyen tanto los aspectos contradictorios como los elementos problemáticos que cuestionan la naturaleza del conjunto de realidades a las que se suele aludir cuando se utiliza el concepto. Así, el establecimiento residencial semi-permanente, o incluso permanente, se acepta como una dimensión del proceso turístico (también por algunos académicos estudiosos del asunto) y, en consecuencia, el turismo residencial adquiere una nueva entidad, en concreto la que se corresponde con una actividad económica generada por la industria turística. El nuevo significado con el que se carga de contenido a la expresión anula la función crítica original -ligada a los usos que de la misma se hacen habitualmente en el ámbito académico- y la sustituye por una función publicitaria -en sintonía con los intereses comerciales de la burguesía cementera-. A partir de ese momento, los agentes más interesados en promover las dinámicas turístico-residenciales redefinen cualquier crítica al turismo residencial como una crítica a las alternativas de progreso que puede crear la industria turística. La repetición reiterada del carácter turístico del turismo residencial no tiene que hacerse explícita pues el propio concepto ya incluye el sustantivo «turismo». Solamente se requiere producir la armonía de la que inicialmente carecen dos términos discordantes mediante estrategias publicitarias destinadas a eliminar cualquier atisbo de conflicto o contradicción (véanse, como ejemplo, las imágenes 1 y 2).

La constante asociación del «turismo residencial» con un mismo tipo de imágenes fija un significado en la mente del receptor que acaba por convertir el término en una «fórmula hipnótica», utilizando la idea de Marcuse (1964). La expresión deja de identificarse con una determinada realidad para pasar a hacerlo con una parte muy específica de la misma: la totalidad contradictoria y problemática es filtrada y preparada para que la opinión pública la perciba de la manera en la que interesa que sea percibida. De tal forma, el carácter «hipnótico» se afianza conforme se anulan los rastros que permiten conectar el concepto, y la realidad a la que ese concepto quiere hacer referencia, con el contexto ambiental, social $\mathrm{y}$, especialmente, político-económico en el que se origina y necesariamente se inserta. Los significados con los que se carga de sentido a la expresión «turismo residencial»a 


\section{Imagen 1 \\ PUBLICIDAD DE LA PROMOTORA MURCIANA POLARIS WORLD}

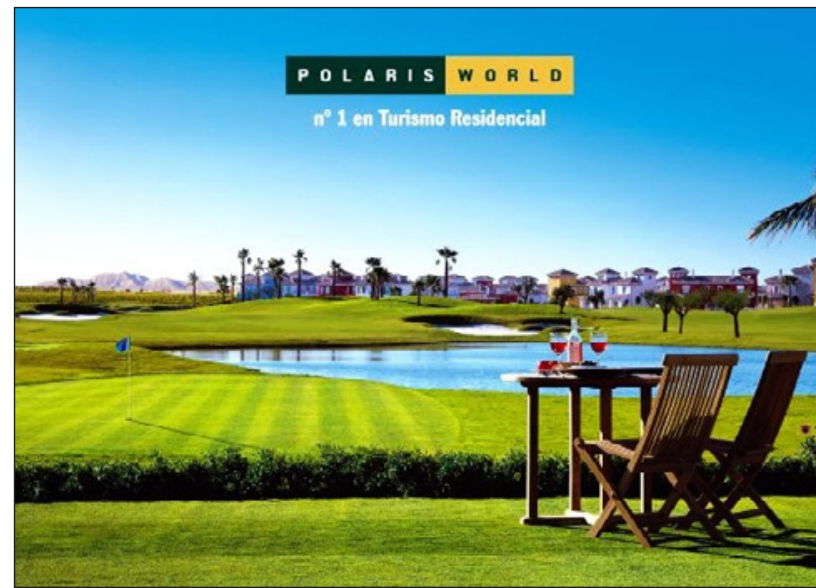

Fuente: web de la empresa. Puede apreciarse la identificación de la construcción de viviendas con la oferta de alojamiento turístico.

\section{Imagen 2}

\section{PUBLICIDAD DE LA PROMOTORA TORREVEJENSE MASA INTERNATIONAL}

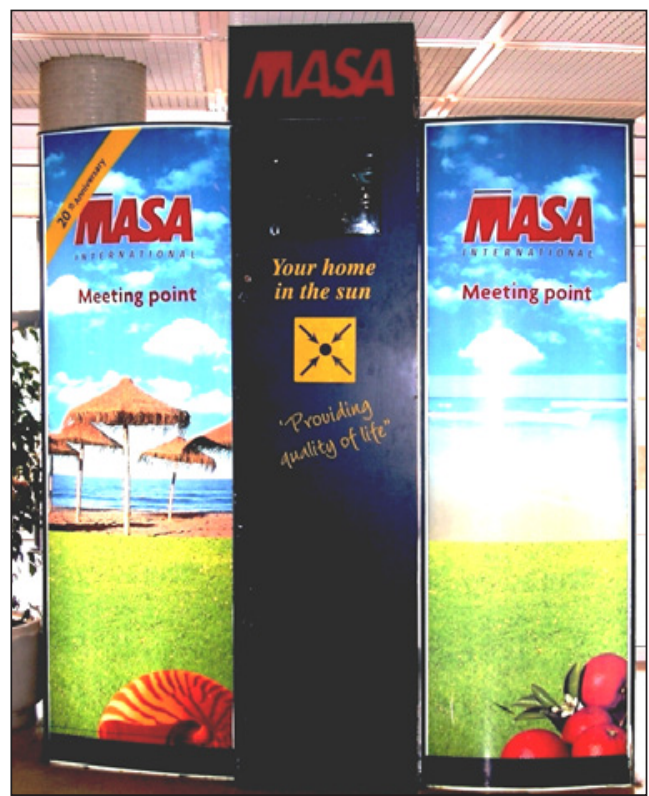

Fuente: fotografía del autor. La traducción del mensaje en inglés es: «Su hogar en el sol. Proporcionando calidad de vida». Adviértase la combinación del texto, orientado a captar flujos internacionales de migración residencial, con imágenes asociadas a experiencias turísticas. 
su vez se integran en sistemas de relaciones donde actúan agentes sociales con intereses particulares. Lo que esos agentes no dicen debe tenerse en cuenta para no quedar inermes ante lo que sí dicen. Así, la instrumentalización ideológica se completa cuando la función referencial del lenguaje es confundida con una función publicitaria, que se vuelve también autoritaria en tanto que trata de disimular precisamente su carácter persuasivo. La nueva definición de la situación produce una serie de significados sobre la realidad que, siendo en gran medida contrarios a las interpretaciones que se derivan de los análisis empíricos, buscan restringir las opciones para formular cuestionamientos críticos. Es decir, la nueva explicación sobre el significado del turismo residencial reduce las posibilidades de entender qué es el turismo residencial.

Pero ¿acaso el turismo residencial carece de elementos constitutivos de naturaleza turística? La respuesta es negativa, evidentemente. Lo que se argumenta es que la burguesía cementera sobredimensiona esos elementos a la vez que encubre, cuando no obvia, los de naturaleza no turística. Por lo tanto, aquí se está plenamente de acuerdo con la sentencia que afirma que el turismo residencial es un fenómeno de naturaleza parcialmente turística. Pero eso es lo mismo que decir que se está de acuerdo con la afirmación que dice que el turismo residencial en una realidad de naturaleza parcialmente no turística. Entonces, ¿es posible cuantificar de algún modo el peso del componente turístico del turismo residencial? En realidad ya se ha hecho.

Por lo que toca al lado de la oferta de alojamiento, más arriba ya se han apuntado las estimaciones que calculan cómo el alojamiento residencial encauzado en la oferta turística reglada es mucho menor que aquel otro que escapa a la legalidad vigente, convirtiéndose, por lo tanto, en una actividad económica situada principalmente al margen de la ley y fomentada por empresas o particulares que poco tienen que ver con el negocio turístico. Del mismo modo, tal y como han subrayado Vera y Díez (2016), resulta absurdo contabilizar como oferta turística o alojamiento comercializable muchas viviendas utilizadas únicamente por sus propietarios como alojamiento vacacional o segunda residencia. Así pues, se conforma una realidad económica caracterizada tanto por su vertebración alrededor de empresas y particulares vinculados al sector inmobiliario como por incurrir en dinámicas especulativas e informales en virtud de las cuales se promueve el descontrol tributario y la opacidad fiscal (Simancas, 2016). A propósito de este asunto, resulta pertinente recalcar como característica definitoria de la economía turístico-residencial no ya su reiteradamente analizada insostenibilidad geoambiental y sociocultural (puede consultarse al respecto la literatura citada en el apartado 2 de este texto) sino, también, su ya perfectamente documentada fragilidad socioeconómica, que aún queda más patente cuando se la compara con la economía turístico-hotelera (León y Suárez, 2016; Perles et al, 2016; Simancas, 2016).

Por lo que respecta al lado de la demanda, Huete (2009) y Huete y Mantecón (2010, 2012) publicaron unos resultados clarificadores a partir del análisis de los datos recogidos mediante una encuesta realizada en 2005, durante la última fase de expansión de la burbuja turístico-inmobiliaria (la muestra de 872 entrevistados era estadísticamente representativa de un universo poblacional compuesto por ciudadanos nacionales de alguno de los 25 países pertenecientes a la Unión Europea en 2005, excepto España, en situación de inactividad laboral -jubilados, pensionistas y amas de casa-, alojados en vivienda particular en 8 municipios de la provincia de Alicante caracterizados por registrar un elevado porcentaje 
de viviendas secundarias). El análisis permitió apreciar como, al tomar en consideración los vínculos administrativos establecidos con España, el 67,9\% de las personas susceptibles de ser catalogadas como «turistas residenciales internacionales» se ajustaban más fácilmente a un estatus de residente que al de un turista, siendo únicamente un 10,9\% los encuestados que encajaban con claridad en un estatus de turista.

\section{CONCLUSIONES}

Los conceptos elaborados por los científicos a partir de las investigaciones que emprenden intentan constituirse en modelos explicativos de la realidad. Cuando un término es apropiado por un sector que, al utilizarlo, no pretende explicar nada sino definir una determinada parte de la realidad con el objetivo de que sus intereses privados se vean beneficiados, entonces se está haciendo ideología (Berger, 1963). En las páginas anteriores se ha planteado una reflexión, basada en las evidencias obtenidas por la experiencia investigadora acumulada, acerca del modo en el que el término «turismo residencial» abandona paulatinamente su adscripción como concepto polémico circunscrito principalmente a las discusiones académicas para, en su lugar, quedar cada día más expuesto a la instrumentalización ideológica por parte de actores sociales interesados en hacer pasar por desarrollo turístico lo que, en esencia, es negocio inmobiliario.

Conseguir que una determinada definición de la realidad adquiera un carácter hegemónico tiene repercusiones prácticas significativas. Aunque no ha de olvidarse (de hecho, la retórica política nos lo recuerda constantemente) que el éxito a la hora de ocupar una posición de centralidad no depende tanto de la habilidad para desplegar los argumentos más consistentes desde el punto de vista de la racionalidad científica acerca de «lo que es verdad», como de los recursos disponibles para proyectar e imponer una determinada interpretación de «lo que es verdad».

Llegados a este punto, en estas conclusiones se invita a la comunidad académica a cuestionar los límites y la vigencia de la expresión como herramienta útil para la investigación en turismo, sobre todo si se considera la politización a la que este término ha sido y está siendo expuesto. Aquí no se propone abandonar la investigación del turismo residencial sino redefinir el objeto de estudio, en relación tanto con el significante como con el significado. Respecto al primero, quizá convendría restringir el uso de esta expresión para aludir solamente a la realidad en la que se está convirtiendo: una etiqueta integrada en una estrategia publicitaria al servicio de intereses político-empresariales vinculados directamente con la economía inmobiliaria. De lo contrario, se corre el riesgo de seguir el juego propuesto por dichos intereses. Respecto al segundo, tal vez sería más conveniente situarse en posiciones similares a las adoptadas por Fernando Vera (como se apuntaba más arriba) y aludir al conjunto de realidades que son objeto de estudio haciendo uso de expresiones menos contaminadas por los discursos ideológicos.

\section{BIBLIOGRAFÍA}

ALEDO, A. (2008): «De la tierra al suelo: la transformación del paisaje y el nuevo turismo residencial», Arbor, vol. 184, n 729, pp. 99-113. 
ALEDO, A.; LOLOUM, T.; ORTIZ, G. y GARCÍA, H. (2013): «El turismo residencial internacional en el nordeste de Brasil: un análisis de partes interesadas», Revista Española de Investigaciones Sociológicas, $\mathrm{n}^{\circ}$ 142, pp. 3-24.

ARONSSON, L. (2004): «Place attachment of vacation residents: between tourists and permanent residents». En Hall, C.M. y Müller, D.K. (eds.) Tourism, Mobility and Second Homes: Between Elite Landscape and Common Ground. Clevedon, Channel View, pp. 75-86.

ASSIS, L.F. (2009): «Segundas residencias y multiterritorialidad en el nordeste brasileño: el aumento del turismo residencial». En Mazón, T., Huete, R. y Mantecón, A. (eds.) Turismo, urbanización y estilos de vida. Las nuevas formas de movilidad residencial. Barcelona, Icaria, pp. 175-191.

BARRANTES, M.P. (2011): «The expansion of real estate tourism in coastal areas: its behaviour and implications», Recreation and Society in Africa, Asia and Latin America, vol. 2, $\mathrm{n}^{\mathrm{o}} 1$, pp. 51-70.

BELL, M. y WARD, G. (2000): «Comparing temporary mobility with permanent migration», Tourism Geographies, vol. 2, nº 1, pp. 97-107.

BENSON, M. y O'REILLY, K. (2009): «Migration and the search for a better way of life: a critical exploration of lifestyle migration», The Sociological Review, vol. 57, $\mathrm{n}^{\circ} 4$, pp. 608-625.

BERGER, P. (1963): Invitation to Sociology. A Humanistic Perspective. New York, Anchor Books.

BIGGAR, J.C. (1980): «Reassessing elderly sunbelt migration», Research on Aging, $\mathrm{n}^{\circ}$ 2, pp. 165-176.

BLÁZQUEZ, M.; CAÑADA, E. y MURRAY, I. (2011): «Búnker playa-sol. Conflictos derivados de la construcción de enclaves de capital transnacional turístico español en El Caribe y Centroamérica», Scripta Nova. Revista Electrónica de Geografía y Ciencias Sociales, XV(368).

BORJA, J. (2003): «La revolución urbana», El País, 20 de abril.

BORJA, J. (2012): «El fin de la anticiudad posmodernista y el derecho a la ciudad en las regiones metropolitanas». En Belil, M.; Borja, J. y Corti, M. (eds.) Ciudades, una ecuación imposible. Barcelona, Icaria, pp. 279-320.

BÖRÖCZ, J. (1996): Leisure migration. A sociological study on tourism. Oxford, Pergamon.

BREUER, T. (2005): «Retirement migration or rather second-home tourism? German senior citizens on the Canary Islands», Die Erde, vol. 136, n 3, pp. 313-333.

CASADO, M.A. (2001): De turistas a residentes: la migración internacional de retirados en España. Tesis doctoral, Universidad de Alicante, España.

COPPOCK, J.T. (ed.) (1977): Second Homes: Curse or Blessing? Oxford, Pergamon.

CROUCHER, S. (2012): «Privileged mobility in an age of globality», Societies, $\mathrm{n}^{\circ} 2$, pp. $1-13$.

DEL PINO, J. (2015): Estructuras residenciales y movilidad. Más allá de la segunda residencia. Madrid, CIS.

DÍAZ, F. y LOURÉS, M.L. (2008): «La globalización de los mercados inmobiliarios: su impacto sobre la Costa Blanca», Ciudad y Territorio. Estudios Territoriales, XL(155), pp. 77-92. 
DOMÍNGUEZ, J.A.; ALEDO, A. y ROIG, B. (2016): «Dificultades epistemológicas y técnicas en encuestas a población elusiva: el caso de los turistas residenciales», Cuadernos de Turismo, $\mathrm{n}^{\circ}$ 37, pp. 135-155.

FUSTER, B.; LILLO, A.; MARTÍNEZ, C. y RAMÓN, A. (2010): «Crecimiento internacional de cadenas hoteleras vacacionales españolas desde una perspectiva global: un estudio de casos», Cuadernos de Turismo, n 25, pp. 69-97.

GASCÓN, J. y CAÑADA, E. (coords.) (2016): Turismo residencial y gentrificación rural. El Sauzal (Tenerife), Pasos.

GAVIRIA, M. (1971): Campo, urbe y espacio de ocio. Madrid, Siglo XXI.

GAVIRIA, M. (1974a): «La producción neocolonialista del espacio», Papers. Revista de Sociología, $\mathrm{n}^{\circ} 3$, pp. 201-217.

GAVIRIA, M. (1974b): España a go-go: turismo charter y neocolonialismo del espacio. Madrid, Turner.

GAVIRIA, M. (1976): El turismo de invierno y el asentamiento de extranjeros en la provincia de Alicante. Alicante, Diputación Provincial.

GIL DE ARRIBA, C. (2011): «Del turismo hotelero al turismo residencial en Marruecos. Entre el negocio inmobiliario y la recreación de imaginarios socioespaciales», Cuadernos de Turismo, $\mathrm{n}^{\circ}$ 27, pp. 471-487.

GONZÁLEZ, R. y MANTECÓN, A. (2014): «Turismo y negocio inmobiliario: la crisis de un modelo de desarrollo», Estudios y perspectivas en turismo, vol. 23, n 4 , pp. 685-705.

GUSTAFSON, P. (2002): «Tourism and seasonal retirement migration». Annals of Tourism Research, vol. 29, n 4, pp. 899-918.

HAAS, W.H. y SEROW, W.J. (1993): «Amenity retirement migration process: a model and preliminary evidence», The Gerontologist, vol. 33, n 2, pp. 212-220.

HALL, C.M.; WILLIAMS, A.M. y LEW, A.A. (2004): «Tourism: Conceptualizations, institutions, and issues». En Lew, A.A.; Hall, C.M. y Williams, A.M. (eds.) A Companion to Tourism. Oxford, Blackwell, pp. 3-24.

HIERNAUX, D. (2009): «Los imaginarios del turismo residencial: experiencias mexicanas». En Mazón, T.; Huete, R. y Mantecón, A. (eds.) Turismo, urbanización y estilos de vida. Las nuevas formas de movilidad residencial. Barcelona, Icaria. Pp. 109-125.

HOF, A. y BLÁZQUEZ, M. (2013): «The Linkages between Real Estate Tourism and Urban Sprawl in Majorca (Balearic Islands, Spain)», Land, vol. 2, n 2, pp. 252-277.

HOGAN, T.D. (1987): «Determinants of the seasonal migration of the elderly to sunbelt states», Research on Aging, $\mathrm{n}^{\circ}$ 9, pp. 115-133.

HOWARD, R. (2009): «The migration of westerners to Thailand: an unusual flow from developed to developing world», International Migration, vol. 47, $\mathrm{n}^{\mathrm{o}}$ 2, pp. 193-225.

HUBER, A. y O'REILLY, K. (2004): «The construction of Heimat under conditions of individualised modernity: Swiss and British elderly migrants in Spain», Ageing and Society, vol. 24, n 3, pp. 327-352.

HUETE, R. (2004): «La imagen social del impacto del turismo sobre el medio ambiente». En Álvarez Sousa, A. (ed.) Turismo, ocio y deporte. La Coruña, Universidad de La Coruña, pp. 287-298.

HUETE, R. (2009): Turistas que llegan para quedarse. Una explicación sociológica sobre la movilidad residencial. Alicante, Publicaciones de la Universidad de Alicante. 
HUETE, R. y MANTECÓN, A. (2010): «Los límites entre el turismo y la migración residencial. Una tipología», Papers. Revista de Sociología, vol. 95, n 3, pp. 781-801. HUETE, R. y MANTECÓN, A. (2012): «Residential Tourism or Lifestyle Migration. Social Problems Linked to the Non-definition of the Situation». En Moufakkir, O. y Burns, P. (eds.) Controversies in Tourism. Wallingford, CABI, pp. 160-173.

HUETE, R.; MANTECÓN, A., y ESTÉVEZ, J. (2013): «Challenges in Lifestyle Migration Research: Reflections and Findings about the Spanish Crisis», Mobilities, vol. 8 , $\mathrm{n}^{\mathrm{o}} 3$, pp. 331-348.

HUETE, R. y TROS-DE-ILARDUYA, M. (2011): «La valorización de los espacios naturales como pretexto para el desarrollo urbanístico en el sudeste de España», Proyección, vol. $5, \mathrm{n}^{\circ} 10$, pp. 102-124.

JAAKSON, R. (1986): «Second-home domestic tourism», Annals of Tourism Research, vol. $13, n^{\circ} 3$, pp. 367-391.

JACKIEWICZ, E. y CRAINE, J. (2010): «Destination Panama: an examination of the migration-tourism-foreign investment nexus», Recreation and Society in Africa, Asia and Latin America, vol. 1, n ${ }^{\circ}$ 1, pp. 5-29.

JANOSCHKA, M. (2009): «The contested spaces of lifestyle mobilities. Regime analysis as a tool to study political claims in Latin American retirement destinations», Die Erde, vol. 140, no 3 , pp. 251-274.

JANOSCHKA, M. (2011): «Habitus and radical reflexivity: a conceptual approach to study political articulations of lifestyle- and tourism-related mobilities», Journal of Policy Research in Tourism, Leisure \& Events, vol. 3, n 3, pp. 224-236.

JANOSCHKA, M. (2013): «Nuevas geografías migratorias en América Latina: prácticas de ciudadanía en un destino de turismo residencial», Scripta Nova. Revista Electrónica de Geografía y Ciencias Sociales, XVII(439).

JURDAO, F. (1978): Turismo residencial y colonización. Tesis doctoral, Universidad del País Vasco, España.

JURDAO, F. (1979): España en venta: compra de suelo por extranjeros y colonización de campesinos en la Costa del Sol. Madrid, Ayuso.

KING, R.; WARNES, A.M. y WILLIAMS, A.M. (2000): Sunset lives: British retirement migration to the Mediterranean. Oxford, Berg.

LEÓN, C. y SUÁREZ, B. (2016): «Los impactos económicos de la residencialización de las áreas turísticas». En Simancas, M. y Mañoso, J. (coords.) La residencialización de las áreas turísticas de Canarias. Santa Cruz de Tenerife, Promotur Turismo Canarias, pp. 65-92.

LEONTIDOU, L. y MARMARAS, E. (2001): «From tourists to migrants, Residential tourism and 'littoralization'». En Apostolopoulos, Y.; Loukissas, P. y Leontidou, L. (eds.) Mediterranean Tourism, Facets of socioeconomic development and cultural change. London and New York, Routledge, pp. 257-267.

LONGINO, C.F.; MARSHALL, V.W.; MULLINS, L.C. y TUCKER, R. D. (1991): «On the nesting of snowbirds: A question about seasonal and permanent migrants», Journal of Applied Gerontology, vol. 10, nº 1, pp. 157-168.

MANTECÓN, A. (2008): La experiencia del turismo. Un estudio sociológico sobre el proceso turístico-residencial. Barcelona, Icaria. 
MANTECÓN, A. (2011a): «La legitimación social como clave explicativa del proceso turístico-residencial», Revista Española de Sociología, n ${ }^{\circ}$ 16, pp. 73-90.

MANTECÓN, A. (2011b): «El proceso del turismo residencial. Análisis sociopolítico de los discursos públicos desde una perspectiva cualitativa», Empiria. Revista de Metodología de Ciencias Sociales, $\mathrm{n}^{\mathrm{o}} 21, \mathrm{pp} .17-38$.

MANTECÓN, A. (2012): «El nexo entre urbanización y turismo. Análisis de la opinión pública», Papers. Revista de Sociología, vol. 97, nº 1, pp. 249-272.

MARCUSE, H. (1964): One-Dimensional Man. Boston, Beacon Press.

MAZÓN, T. (1987): La urbanización de la Playa de San Juan: un espacio turísticoresidencial. Alicante, Instituto de Estudios Juan Gil-Albert.

MAZÓN, T. (2006): «El turismo litoral mediterráneo ¿políticas turísticas o desarrollo inmobiliario?». En Rodríguez, J.A. (ed.) Sociología para el futuro. Barcelona, Icaria, pp. 301-310.

MCHUGH, K.E.; HOGAN, T.D. y HAPPEL, S.K. (1995): «Multiple residence and cyclical migration: A life course perspective», Professional Geographer, ${ }^{\circ}$ 47, pp. 251-267.

MCWATTERS, M. (2008): Residential tourism. (De)constructing paradise. Bristol, Buffalo and Toronto, Channel View.

MEMBRADO, J.C. (2015): «Migración residencial y urbanismo expansivo en el Mediterráneo español», Cuadernos de Turismo, n 35, pp. 259-285.

MONREAL, J. (dir.). (2001): Un nuevo mercado turístico: jubilados europeos en la Región de Murcia. Murcia, Universidad de Murcia.

MOROTE, A.F.; SAURÍ, D. y HERNÁNDEZ, M. (2016): «Residential Tourism, Swimming Pools, and Water Demand in the Western Mediterranean», Professional Geographer, 1-11.

MOSS, L. (ed.) (2006): The amenity migrants: seeking and sustaining mountains and their cultures. Wallingford, CABI.

MÜLLER, D.K. (2002): «German second homeowners in Sweden: some remarks on the tourism-migration-nexus», Revue Européenne des Migrations Internationales, vol. 18, $\mathrm{n}^{\mathrm{o}} 1$, pp. 67-86.

MURRAY, I. (2015): Capitalismo y turismo en España. Barcelona, Alba Sud.

NIGAM, D. y NARULA, V.K. (2009): «'India brilla’ y el turismo residencial». En Mazón, T.; Huete, R. y Mantecón, A. (eds.) Turismo, urbanización y estilos de vida. Las nuevas formas de movilidad residencial. Barcelona, Icaria, pp. 209-219.

NUDRALI, F.O. y O'REILLY, K. (2009): «Taking the risk: the British in Didim, Turkey». En Benson, M. y O'Reilly, K. (eds.) Lifestyle migration: expectations, aspirations and experiences. Aldershot, Ashgate, pp. 137-149.

O'REILLY, K. (2000): The British on the Costa del Sol. Transnational identities and local communities. London, Routledge.

O'REILLY, K. (2003): "When is a tourist? The articulation of tourism and migration in Spain's Costa del Sol», Tourist Studies, vol. 3, n 3, pp. 301-317.

O'REILLY, K. (2007): «Emerging tourism futures: residential tourism and its implications». En Geoffrey, Ch. y Sibley, R. (eds.) Going abroad: travel, tourism, and migration. Newcastle, Cambridge Scholars Publishing, pp. 144-157. 
ONO, M. (2008): «Long-stay tourism and international retirement migration: Japanese retirees in Malaysia». En Yamashita, S.; Minami, M.; Haines, D.W. y Eades, J.S. (eds.) Transnational migration in East Asia: Japan in a comparative focus (Senri Ethnological Reports 77). Osaka, National Museum of Ethnology, pp. 151-162.

ORTEGA VALCÁRCEL, J. (1975): Residencias secundarias y espacio de ocio. Valladolid, Universidad de Valladolid.

PERLES, J.F.; RAMÓN, A.B.; SEVILLA, M. y MORENO, L. (2016): «Unemployment effects of economic crises on hotel and residential tourism destinations: the case of Spain», Tourism Management, $\mathrm{n}^{\circ}$ 54, pp. 356-368.

RAMÓN, A.B. (2002): La expansión internacional del sector hotelero español. Alicante, CAM.

RAMÓN, A.B. (2010): Evolución en las estrategias de expansión internacional del sector turístico vacacional: el papel de las empresas españolas en Latinoamérica. Santiago de Chile, CEPAL, Colección Desarrollo Productivo, núm.189.

RAYA, P. (2003): «El turismo residencial en el litoral andaluz», Estudios Turísticos, $\mathrm{n}^{\circ}$ 155/156, pp. 179-196.

REQUEJO, J. (2007): «Turistas: del concepto legal a la compleja realidad del actual panorama español», Estudios Turísticos, n 172/173, pp. 147-156.

RODRÍGUEZ, V. (2001): «Tourism as a recruiting post for retirement migration», Tourism Geographies, vol. 3, n 1, pp. 52-63.

RODRÍGUEZ, V. (2004): «Turismo residencial y migración de jubilados», Mediterráneo Económico, $\mathrm{n}^{\circ}$ 5, pp. 233-253.

SALVÀ, P. (1978): Aproximación al conocimiento de la transformación del espacio rural en la Serra de Tramuntana de la isla de Mallorca. Tesis doctoral, Universidad de Barcelona, España.

SALVÀ, P. (1980): «Las funciones residencial y de ocio como elementos de transformación del espacio rural de la Serra de Tramuntana de la Isla de Mallorca», Trabajos de Geografía, no 35, pp. 163-172.

SALVÀ, P. (1984): «Las variaciones estructurales y morfológicas en el espacio rural de la Isla de Mallorca como consecuencia del impacto del turismo de masas». En VV.AA. Coloquio Hispano-Francés sobre espacios rurales. Madrid, Ministerio de Agricultura, Alimentación y Medio Ambiente, Tomo I, pp. 219-230.

SALVÀ, P. (1985a): «Turisme i canvi a l'espai de les Illes Balears», Treballs de la Societat Catalana de Geografia, no 2, pp. 17-32.

SALVÀ, P. (1985b): «Les conséquences du developpement touristique sur les activités agraires dans l'espace des îles Baléares». En VV.AA. Le tourisme contre l'agriculture. París, ADEF, pp. 67-76.

SALVA, P. (2002a): «Tourist development and foreign immigration in Balearic Islands», Revue Européenne des Migrations Internationales, vol. 18, $\mathrm{n}^{\circ}$ 1, pp. 87-101.

SALVÀ, P. (2002b): «The complex human mobility flows in the Mediterranean Region: The case of Balearic Islands as phenomenon type 'New California'». En Montanari, A. (ed.) Human Mobility in a Borderless World? Roma, Società Italiana de Geografia, pp. 243-258. 
SALVÀ, P. (2005): «Procesos, pautas y tendencias del turismo residencial en las Islas Baleares: ¿inmigrantes de lujo o turistas de larga estancia?». En Mazón, T. y Aledo, A. (eds.) Turismo residencial y cambio social. Nuevas perspectivas teóricas y empíricas. Alicante, Aguaclara, pp. 281-302.

SATO, M. (2001): Farewell to Nippon: Japanese lifestyle migrants in Australia. Melbourne, Trans Pacific Press.

SILVERSTEIN, M. y ZABLOTSKY, D.L. (1996): «Health and social precursors of later life retirement-community migration», Journal of Gerontology, vol. 51, n 3, pp. 150-156.

SIMANCAS, M. (2016): «La residencialización de los establecimientos de alojamiento extrahoteleros». En Simancas, M. y Mañoso, J. (coords.) La residencialización de las áreas turísticas de Canarias. Santa Cruz de Tenerife, Promotur Turismo Canarias, pp. 231-262.

SMITH, S.K. y HOUSE, M. (2007): «Temporary migration: a case study of Florida», Population Research and Policy Review, vol. 26, n 4, pp. 437-454.

SPEARE, A. y MEYER, J.W. (1988): «Types of elderly residential mobility and their determinants», Journal of Gerontology, vol. 43, $\mathrm{n}^{\circ} 3$, pp. 74-81.

TALAVERA, F. (1982): Lago de Chapala. Turismo residencial y campesinado. Guadalajara, Instituto Nacional de Antropología e Historia, Centro Regional de Occidente.

VALENZUELA, M. (1974): «El Escorial: de Real Sitio a núcleo turístico residencial», Anales del Instituto de Estudios Madrileños, $\mathrm{n}^{\circ}$ 10, pp. 363-402.

VERA, F. (1987): Turismo y urbanización en el litoral alicantino. Alicante, Instituto de Estudios Juan Gil-Albert.

VERA, F. (2005a): «El auge de la función residencial en destinos turísticos del litoral mediterráneo: entre el crecimiento y la renovación», Papers de Turisme, n 37/38, pp. 95-114.

VERA, F. (2005b): «El territorio ¿argumento del turismo?». En Romero, J. y Alberola, M. (eds.) Los límites del territorio: El País Valenciano en la encrucijada. Valencia, Universidad de Valencia, pp. 293-297.

VERA, F. (2006): «Agua y modelo de desarrollo turístico: la necesidad de nuevos criterios para la gestión de los recursos», Boletín de la Asociación de Geógrafos Españoles, 42, pp. 155-178.

VERA, F. y DÍEZ, D. (2016): «Espacios y destinos turísticos», Canelobre, nº 66, pp. 85-97.

VISSER, G. (2004): «Second homes: reflections on an unexplored phenomenon in South Africa», Current Issues in Tourism, vol. 9, n 4/5, pp. 351-383.

WALTERS, W.H. (2002): «Later-life migration in the United States: A review of recent research», Journal of Planning Literature, vol. 17, $\mathrm{n}^{\circ}$ 1, pp. 37-66.

WILLIAMS, A.M. y HALL, C.M. (2000): «Tourism and Migration: New Relationships between Production and Consumption», Tourism Geographies, vol. 2, n 1, pp. 5-27.

WILLIAMS, A.M. y HALL, C.M. (2002): «Tourism, migration, circulation and mobility: the contingencies of time and place». En Hall, C.M. y Williams, A.M. (eds.) Tourism and migration: new relationships between production and consumption. London, Kluwer Academic Publishers, pp. 1-52.

WILLIAMS, A.M.; KING, R.; WARNES, A.M. y PATTERSON, G. (2000): «Tourism and international retirement migration: new forms of an old relationship in southern Europe», Tourism Geographies, vol. 2, nº 1, pp. 28-49. 